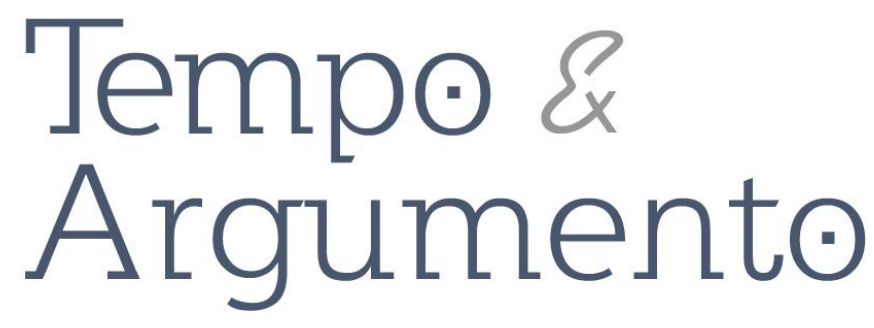

\title{
Autonomia, espacialidades e novas sociabilidades no Tempo Presente: a experiência zapatista
}

Resenha da obra:

BASCHET, Jérôme. Podemos gobernarnos nosotros mismos: La autonomía, una política sin el Estado. Chiapas: Ediciones Cideci, 2017, 150 p.

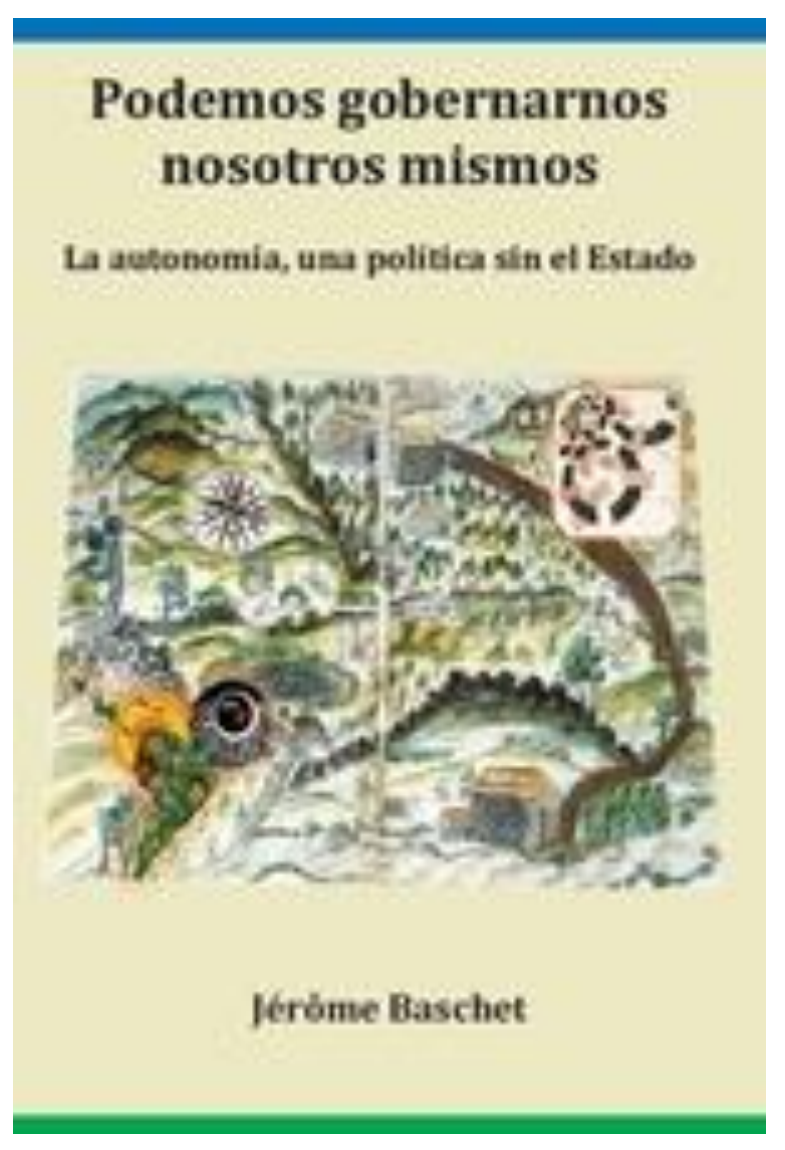

\section{Autor da resenha}

Rodrigo de Morais Guerra Mestrando em História pela Universidade Federal do Rio Grande do Norte (UFRN). Natal, RN - BRASIL rodrigo.morais.guerra@gmail.com orcid.org/0000-0001-9826-9240

\section{Para citar esta resenha:}

BASCHET, Jérôme. Podemos gobernarnos nosotros mismos: La autonomía, una política sin el Estado. Chiapas: Ediciones Cideci, 2017, 150 p. Resenha de: GUERRA, Rodrigo de Morais. Autonomia, espacialidades e novas sociabilidades no Tempo Presente: a experiência zapatista. Revista Tempo e Argumento, Florianópolis, v. 11, n. 28, p. 534 - 539. set/dez. 2019.

DOI: 10.5965/2175180311282019534

http://dx.doi.org/10.5965/2175180311282019534 
Consagrado pelos seus estudos sobre o medievo, Jérôme Baschet nos propõe com “Podemos gobernarnos nosotros mismos: La autonomia, una política sin el Estado” uma nova perspectiva acerca do seu trabalho como historiador, bem como, acerca das relações político-sociais do Tempo Presente. Professor da Universidad Autónoma de Chiapas, desde 1997, Baschet vivenciou o enfervecido contexto mexicano de fins do século XX e presenciou um dos momentos mais marcantes da história dos novos movimentos sociais latino-americanos: a insurgência zapatista para o mundo no $1^{\circ} \mathrm{de}$ janeiro de 1994. Neste livro, o historiador adentra ao complexo universo zapatista, explora suas espacialidades e nos oferece novas reflexões a respeito das (con)vivências em sociedade e seus desafios frente a uma pluralidade de mundos que coexistem em nossas ricas diferenças culturais.

Oriunda de uma verdadeira imersão intelectual e antropológica, a pesquisa de Baschet resulta em um estudo que tem como problemática central compreender de forma mais aprofundada as sociabilidades zapatistas, a partir de uma análise ampla do conceito de autonomia e seus efeitos. Para tanto, a obra gira em torno de duas perguntas basilares: "o que pode ser uma política da autonomia?" e "há outras opções frente a devastação capitalista?". A fim de endossar este debate, temos, logo de início, uma distinção política que polariza a problemática em questão por meio de duas formas, não apenas distintas, mas antagônicas, de exercer um governo: a política de arriba e a política de abajo. Como forma política de arriba, temos uma política que segue as instituições do Estado moderno, englobando seus partidos políticos, toda a classe política e todo o seu aparato burocrático; por outro lado, como forma política de abajo, temos uma política que segue estritamente o povo. Para além de suas distinções estruturais, essas duas formas políticas diferem, essencialmente, em suas manifestações de poder e participações plenamente democráticas, assim, ambas as formas políticas apresentam-se numa condição de total incompatibilidade, de modo que, a primeira (de arriba), caracterizada, por desapropriar o povo de suas capacidades de auto-organização, por meio de seus mecanismos institucionais, não admite o pleno exercício da segunda (de abajo); que, por sua vez, não tem como ser exercida se não combater a primeira e o seu monopólio na centralidade do poder. Portanto, diante de tal cenário, a autonomia 
zapatista incorpora um caráter anti-institucional: uma forma política de abajo, exercida por e para o povo e constante combatente à centralidade do poder político heterônomo estatal (de arriba).

Sendo assim, a autonomia zapatista, uma configuração governamental políticopopular, fruto de um processo histórico de lutas e resistências frente à imposição do poder (o que caracteriza a violência) de cima para baixo, ocupa o cerne do texto com sua conceituação e aplicabilidades práticas. A autonomia surge, destarte, não como um sonho ou devaneio dos indígenas de Chiapas, mas como uma arma de resistência, como um refúgio para a proteção de suas vidas, como uma resposta ao Estado moderno heterônomo capitalista e, incessantemente, mantém seu processo construtivo ativo, diante das necessidades de adaptação e autotransformação, a partir dos novos desafios propostos pela experiência vivida. Dessa forma, a autonomia zapatista materializa-se numa configuração que Jérôme Baschet (2017) distingue em três dimensões: a comunidade, ou seja, o modo de organização dos povos indígenas, assumindo a dimensão coletiva do viver; o território, compreendido como as partes habitadas e cultivadas, mas também bosques e montanhas, como o lugar próprio da consistência e singularidade da comunidade; e a terra, dimensão caracterizada por Baschet como "potência de vida englobante", que seria, portanto, sua vida, sua tradição, sua cultura, sua visão do mundo, sua coesão e sua identidade (BUENROSTRO Y ARELLANO, 2002, p. 17). Em sua aplicabilidade prática, a experiência zapatista ainda propõe uma organização política articulada em outros três níveis: comunidade, município e zona, nos quais, cada um dispõe de mecanismos vigilantes de seus plenos funcionamentos enquanto política de abajo, tais como: assembleias e autoridades eleitas, Conselho municipal autônomo e Juntas de bom governo, conformando, assim, a estrutura organizativa política autônoma de abajo zapatista.

Ao ser estabelecida uma estrutura política para gerir um sistema autônomo, podemos nos indagar sobre a real horizontalidade neste governo, pois, se há instituições organizativas das sociabilidades dos sujeitos, presume-se que há hierarquias e superioridades. Entretanto, a existência de uma estrutura reguladora do poder não deve ser confundida com um sistema de dominação através do poder. O poder, em sua 
essência, jamais será singular, mas sempre plural, como nos advertiu Hannah Arendt (2010); o poder aparece, pois, como manifestação organizativa das aspirações coletivas. Dessa forma, a autonomia, por mais que se estabeleça sob a responsabilidade de promover uma sociedade em que todos estão em pé de igualdade e todos têm responsabilidade sobre todos, ainda assim, é um modelo político no qual as relações de poder são fundamentais para a sua existência e sobrevivência. Para lidar com essa questão, os zapatistas dispõem de mecanismos reguladores que preservem a forma política de abajo de se autogovernar, para tanto, o seu já consagrado oximoro mandar obedecendo é um dos pilares de sustentação do bem caminhar da autonomia. Algumas características fundamentais do mandar obedecendo que regulam esta dinâmica são: os mandatos se concebem como cargos realizados para servir à comunidade, sem remuneração, nem nenhum tipo de vantagem material; ninguém se autopropõe para as funções e são as próprias comunidades que solicitam a quem consideram que podem exercê-las; os cargos são assumidos sobre a base de uma ética efetivamente vivida do serviço à coletividade; e os cargos sempre são exercidos de maneira colegiada e sob o controle permanente tanto da "Comissão de vigilância", responsável por conferir as contas dos conselhos, quanto da população, à vista que os cargos são revogáveis a qualquer momento, fazendo valer a máxima de que o poder só é efetivado quando a palavra e o ato não se divorciam (ARENDT, 2010, p. 249).

Ademais das características descritas que garantem a governabilidade autônoma, o mandar obedecendo engloba um outro aspecto de fundamental importância que consiste na "desespecialização" das tarefas políticas. A partir de uma não especialização dos representantes do povo no governo, o exercício da autoridade se cumpre desde uma posição de não saber e "asumir ese no saber es lo que permite ser una 'buena autoridade', la cual se esfuerza por escuchar y aprender de todos, sabe reconocer sus errores y deja que la comunidad la guíe en la elaboración de las decisiones" (BASCHET, 2017, pp. 32-33). Logo, permitindo que o mandar obedecendo constitua uma "sólida defensa contra el riesgo de una separación entre gobernantes y gobernados (BASCHET, 2017, p. 33). 
Por fim, "Podemos gobernarnos nosotros mismos" traz importantes contribuições para o campo teórico no estudo da autonomia. Uma primeira reflexão diz a respeito de que uma política não-estatal não exige, necessariamente, um horizontalismo puro: há momentos em que o povo manda e o governo obedece, e há momentos em que o povo obedece e o governo manda, configurando, dessa forma, o exercício coletivo do poder, como já apontamos, o que, por sua parte, não dissocia inteiramente as duas relações inversas, mas as coloca numa condição de reciprocidade. Desta forma, não se trata de um poder heterônomo e, tampouco, de uma perfeita horizontalidade, mas o exercício de uma coletividade do poder que permite o pleno funcionamento da autonomia e não põe em risco toda a dinâmica de governo. Posto isso, enquanto que o Estado heterônomo emprega um modelo de delegação dissociativa, ou seja, na articulação com a estrutura social, almeja produzir e reproduzir a separação entre governantes e governados, concentrando o "poder-sobre" em um aparato burocrático e um grupo isolado; a autonomia sugere um modelo de delegação não dissociativa, ou seja, busca restringir ao máximo a separação entre governantes e governados, através de mecanismos ativos no combate à dissociação e na manutenção do uso efetivo da potência coletiva.

Por último, mais uma importante provocação levantada por Baschet (2017) consiste na eterna condição de inacabada da autonomia, o que o autor coloca como "um processo sem fim". A autonomia, desse modo, consiste, portanto, em uma manifestação política incompleta e, necessariamente, infinita, pois, a pretensão de se criar uma sociedade ideal que afirmaria ter alcançado seu objetivo e sua forma última, completa e realizada, significaria, imediatamente, a morte da autonomia, haja vista que a autonomia, tal qual o rio de Heráclito, está, cotidianamente, transformando e transformando-se, destacando, dessa forma, uma condição paradoxal para a sua vigência: a autonomia só existe enquanto ela não é. Diferentemente das utopias normativas, que partem de pressupostos e objetivos finais a priori, a autonomia parte das singularidades de suas vivências concretas, utilizando-se da sua inacabável capacidade de adaptar-se e reinventar-se, o que os zapatistas tratam como "buscar el modo", ou seja, descartar toda resolução pronta, abstrata e geral. Opondo-se, drasticamente, às lógicas constitutivas do Estado capitalista, a autonomia "es una política procesual que no puede ser 
(pre)determinada por ningún texto; se ubica en las antípodas del fetichismo de la Constitución" (BASCHET, 2017, p. 64). Portanto, a busca pela autonomia consiste na elevação do espírito inquieto, na permanente insatisfação, na constante vigilância frente aos erros e incansáveis esforços para retificá-los. Trata-se de uma experimentação que busca seu caminho, caminhando.

Em suma, o autogoverno zapatista não é mais que uma expressão da capacidade coletiva de organizar-se e afirmar formas de vidas próprias aos avanços da coletividade e dignidade compartilhada. Muito mais do que uma utopia, a autonomia mostra-se como uma arma de resistência, como uma "potência destituinte" (BASCHET, 2017), como um caminho em busca da emancipação abarcado por uma dupla dimensão: destruiçãonegação do mundo capitalista que ameaça a vida indígena; e construção-afirmação de uma nova sociabilidade possível. A experiência zapatista extrapola os limites das simplistas interpretações da autonomia, nos propõe novos modelos de espacialidades e nos faz repensar as sociabilidades regidas por um Estado heterônomo: valorosas contribuições em tempos de crises políticas no Brasil, na América-Latina e no mundo. 
Revista Tempo e Argumento Volume 11 - Número 28 - Ano 2019 tempoeargumento@gmail.com 